\title{
MORPHOLOGICAL ANALYSIS OF LANDSLIDES IN EXTREME TOPOGRAPHY BY UAS-SfM: DATA ACQUISITION, 3D MODELS AND CHANGE DETECTION
}

\author{
T. W. Yeh ${ }^{1}$ and R. Y. Chuang ${ }^{1}$ \\ ${ }^{1}$ Department of Geography, National Taiwan University, Taipei, Taiwan \\ (r07228020@ntu.edu.tw)
}

KEY WORDS: Unmanned Aerial Vehicles, Multi-View Stereo, Point Clouds, Mass Wasting, Landslides, Extreme Topography

\begin{abstract}
:
Landslides are one major kind of natural disasters and geomorphological processes on Earth's surface. Accurate geodetic observations are crucial for understanding morphological changes, providing a quantitative basis of further research in surface process and hazard management. In recent years, the development of UAVs and SfM technology enhance research to build high quality digital surface models of landforms with low budget and efficiency. In areas of extreme topography where landslides occur on steep slopes, however, it is required to specifically design the UAV-SfM workflow to keep the data quality. This study aims to use UAS-SfM workflow to develop a low-cost, efficient methodology to detect detailed morphological change of landslide morphology in extreme topography. The study focuses on examining results of different flight design and GCPs distribution geometry, which are important components in the workflow. In addition, we applied a mathematical model to compare point clouds to calculate volumetric change of the landslide with reduced distortion.
\end{abstract}

\section{INTRODUCTION}

The process of mass wasting is one fundamental question in earth sciences, which is highly related to research in geomorphology and hazard management. In order to analyse the process, it is important monitor and detect surficial changes of landslides, and geodetic approaches are often used to conduct such observations. Among varied geodetic approaches, photogrammetric-based methods can provide accurate estimates of volumetric changes, which is very useful for understanding the amount and distribution of landslide activities.

In recent years, the evolution of Structure from Motion (SfM) has become a popular method in the field of image-based 3D reconstruction. In contrast to traditional photogrammetry, the blooming of SfM commercial and open-sourced software assists researchers to produce $3 \mathrm{D}$ models from images which is photographed by non-metric cameras without full information of processing complex photogrammetric parameters. Similarly, the thriving of Unmanned Aerial Systems (UAS) provides easy access to the non-professionals. Consumer-graded UAVs have reduced the proficiency of aerial photography, which made such UAVs a convenient platform for implement low-altitude, close to medium-ranged remote observation.

Due to the reduced cost and threshold of manipulation, SfM and UAS have been graduate accepted in geoscience as a survey technique to acquire detail topographical information of various landforms (Eltner et al., 2016).

In many kinds of geomorphic studies, landslides are rather difficult to monitor. Compared with traditional geodetic techniques, UAV-SfM workflow allow researchers to quantify and analyse the morphological change of landslides in a laboursaving, safe and efficient way. Nonetheless, the characteristics of $\mathrm{SfM}$, which cannot straightforwardly infer uncertainty following traditional photogrammetric algorithm, inspire studies to further examine the source of errors from flight design, geometry of ground-reference points and photography settings in order to achieve high precision of 3D models. So far, the application of the UAS-SfM method is mainly limited at creeping and avalanches at rather gentle slopes where in-situ installation of ground control points (GCPs) is feasible (Niethammer et al., 2012; Lucieer et al., 2014; Turner et al., 2015; Clapuyt et al., 2017; Warrick et al., 2019). The quality and procedure of the UAS-SfM are not well examined at landslides in extreme topography, which occurs vary a frequently in active mountain belts.

Therefore, the purpose of this study aims to develop a suitable UAS-SfM workflow to landslides with extreme topography and examine how the procedures is applied to detect morphological changes. We tested different flight design and GCP geometry to examine their data quality for observing landslide volumes.

\section{STUDY AREA}

In order to examine how UAS-SfM applied to landslides in extreme topography, we chose the study area, which is located st the upstream Sinwulu river gorge, western side of Lidao village, Haiduan township, Taitung County, southern Taiwan ( $23^{\circ} 11^{\prime} 0^{\prime \prime}$ $\left.\mathrm{N}, 121^{\circ} 01^{\prime} 05^{\prime \prime}\right)$. The area is within the mountain belt of the island of Taiwan where steep slope and frequent landslides exit. In recent years in this area, a lot of landslides occurred after a catastrophic rainfall event in 2009. We chose one landslide, which destroyed old highway and a new bridge was built to bypass the landslide, providing an excellent location to conduct observation about $60 \mathrm{~m}$ far from the target (Figure 1).

The landslide belongs to a metamorphic rock area of south eastern Taiwan with foliated structures. The extent of the landslide is about $200 \mathrm{~m}$ width and $300 \mathrm{~m}$ height. The slope is higher than 40 degrees. The landslide surface has some debris on the slope and forms a talus cone at the bottom of the landslide. The rugged topography and continuing sliding colluvial deposits make difficult for any instrumentation. Therefore, we have to measure ground control points on the slope remotely. 


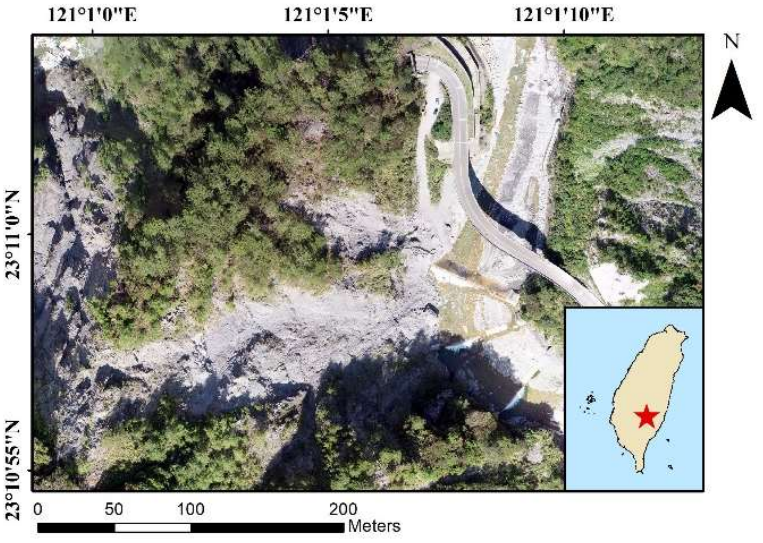

Figure 1. Orthoimage of study area

\section{METHODOLOGY}

Our process includes field work, SfM processing and multi temporal data comparison. The field works have been done twice on January and October, 2019, which cross the local rain season. The whole SfM procedures were implemented in Agisoft Photoscan (version 1.3.5) which automatically process selfcalibration SfM to produce point cloud, orthophotos and mesh and straightforward error assessment of the model. The third part compared two periods point clouds of the landslide by $\mathrm{M} 3 \mathrm{C} 2$ algorithm (Lague et al., 2013) in Cloudcompare to calculate the distance change of topography movement (Figure 2).

Flight plan design and ground control point network are two decisive components determining the quality of products and suitability of the workflow. In the field work component, we implemented 4 kinds of flight plan and 4 kinds of GCPs spreading planning and multi-temporal morphological analysis.

\begin{tabular}{|c|c|}
\hline \multicolumn{2}{|c|}{ 1. Field Work Phase } \\
\hline $\begin{array}{l}\text { Flight Plan } \\
\text { Design }\end{array}$ & $\begin{array}{c}\text { GCPs } \\
\text { measurement }\end{array}$ \\
\hline $\begin{array}{l}\text { 2. Data } \\
\text { Processing } \\
\text { Phase }\end{array}$ & \begin{tabular}{c}
\multicolumn{1}{|c|}{} \\
Processing
\end{tabular} \\
\hline $\begin{array}{c}\qquad \\
\text { Accuracy } \\
\text { Assessment }\end{array}$ & $\begin{array}{c}\text { M3C2 } \\
\text { Distance \& } \\
\text { Uncertainty }\end{array}$ \\
\hline & $\begin{array}{c}\downarrow \\
\text { Rodriquez } \\
\text { Rotaion }\end{array}$ \\
\hline $\begin{array}{l}\text { 3. Data } \\
\text { Comparison } \\
\text { Phase }\end{array}$ & $\begin{array}{c}\qquad \\
\text { Volume } \\
\text { Estimation }\end{array}$ \\
\hline
\end{tabular}

Figure 2. Work flow of this study

\subsection{Flight Plan}

We designed two different ways of arrangements of flight lines. One was semi-circular in shape for every single flight line and surrounding the landslide target. The lines were arranged vertically with $10 \mathrm{~m}$ difference between each other to kept $80 \%$ lateral overlapping rate with at least $50 \mathrm{~m}$ photography distance. This flight design ensured that aerial images include different orientations which can improve $\mathrm{SfM}$ performance as many guidelines recommended. The other was straight flight lines across the target on different elevations with $10 \mathrm{~m}$ spacing between each other. The landslide was considered as high angle plane and photography works followed aerial photogrammetry procedures.

We used two kinds of UAVs: DJI Phantom 4 Pro (P4P) and Phantom 4 RTK (P4RTK). P4RTK is equipped with specific antenna to have direct link to a ground RTK-GNSS base station and automatically applies image position offset to calculate camera centre, which theoretically acquire more accurate exterior parameters of camera than P4P. By manipulating 2 kinds of platforms, it is an opportunity to examined how the performance of different UAVs for constructing 3D models differ under the condition that in-situ GCPs are not available and georeferenced data relies only on UAV recorded exterior parameters of images.

In summary, two kinds of flight design and two kinds of UAVs make four kinds of flight design: semi-circular flight line with $\mathrm{P} 4 \mathrm{P}$, semi-circular flight line with P4RTK, straight flight line with P4P and straight flight with P4RTK (Figure 3, 4). They were all operated manually without flight mission planer software.

In addition, we kept most parameters kept the same in 4 kinds of flight plan. The photography angle was $60-70$ degrees off the nadir to make the aerial images roughly fit the extent of the landslide. This setting ensured that more tie points could be detected to improve the completeness of models especially for high angle target (Jaud et al., 2019). the photography distance kept at least $50 \mathrm{~m}$, lateral and forward overlapping rates are both $80 \%$, and the ground sample distance is at least $1.37 \mathrm{~mm}$. The camera type was DJI Phantom 4 series built-in camera, which focus length is $8.8 \mathrm{~mm}$, image size is $5742 \times 3648$ pixel, the sensor size is $13.2 \times 8 \mathrm{~mm}$.

\subsection{Ground Control Points}

The deployment of ground reference points is another issue in field survey planning. We installed 4 GCPs on the bridge and on the ground, which were measured by RTK-GPS. 5 GCPs and 13 Check points were arranged on the landslide surface based on discernible surface features on the landslide (Agüera-Vega et al., 2018) and they were all measured by total station (Figure 4). Because of the convex shape of model, we tested four ways of GCPs arrangement to examine how the GCPs distribution geometry effect the accuracy of model: full 9 GCPs, 5 GCPs on landslide surface only, 4 ground GCPs only and no GCPs. The coordinate system is TWD97 TM2 (ESPG::3826).

\subsection{Dense Point Cloud Comparison}

Two different periods of 3D model comparison and detailed volumetric estimation were the core problems. The geometries of the ground reference points were not the same especially on the landslide surface. To find the GCPs that can be used for both periods, we applied the GCPs geometry of 2nd survey on 1st model in SfM processing, and set 4 GCPs on the bridge as control points and 5 points on landslide as check points in geo-reference step, assuming that the 4 ground GCPs are stable. The result showed that the error of 5 check points is smaller than GSD so that they can be seen unchanged during 2 surveys. The ground reference points in the stable area were selected as common GCPs of two models so that two periods models share the same geo-reference framework. In this study, all 5GCPs on the landslide were considered as common GCPs. 
Point clouds, which are the first products after SfM processing, were used to be the source of different periods comparison. Unlike DSM or orthoimages, point cloud can keep original 3D spatial information without gridding and projecting, which may lose detailed information, especially when the target is on a steep slope. The $\mathrm{M} 3 \mathrm{C} 2$ algorithm, which calculate distance between two clouds along sub-regional surface normal and take its roughness and density into consideration, is used to detect point cloud change. The M3C2 not only calculate small region point cloud distance change but also set the significant change criteria, which is the uncertainty of distance of change. The M3C2 values and its distance uncertainty were taken as $Z$ values to multiply manually contoured significant change area to create DSM and then calculate the volume change and errors estimation in ArcGIS (Stumpf et al., 2015; Esposito et al., 2017).

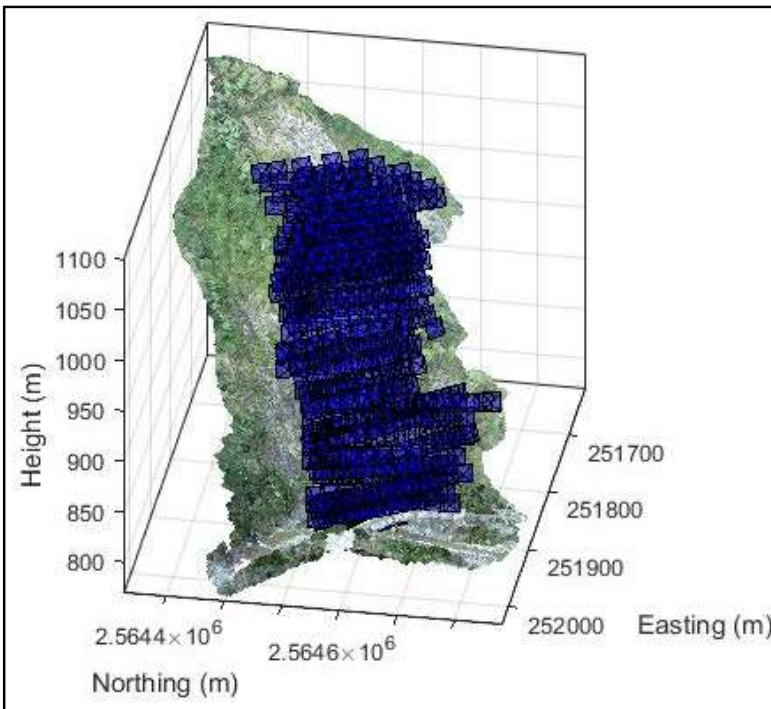

(a)

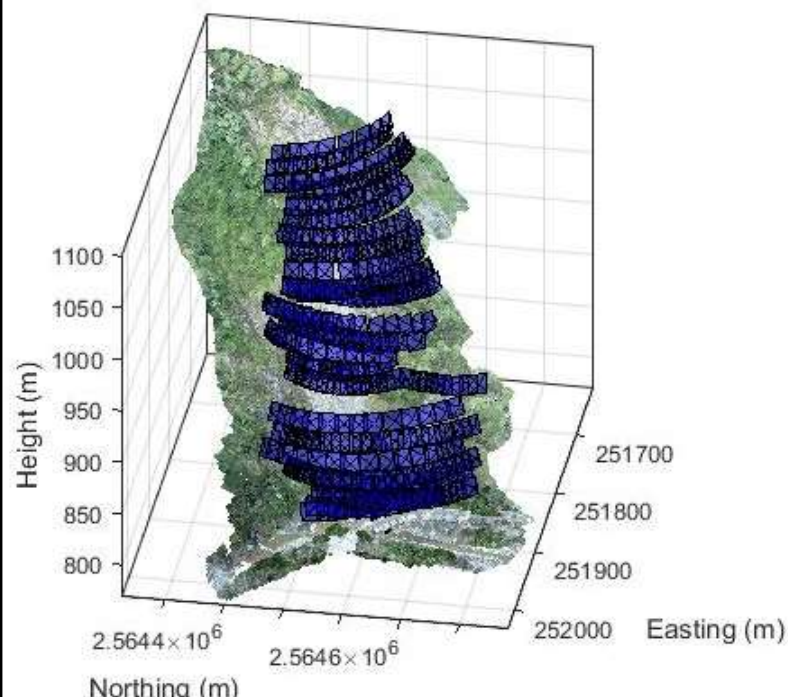

(b)

Figure 3. Camera position and orientation of flight plans operated by P4P. (a) straight flight lines and (b) semi-circular flight lines.

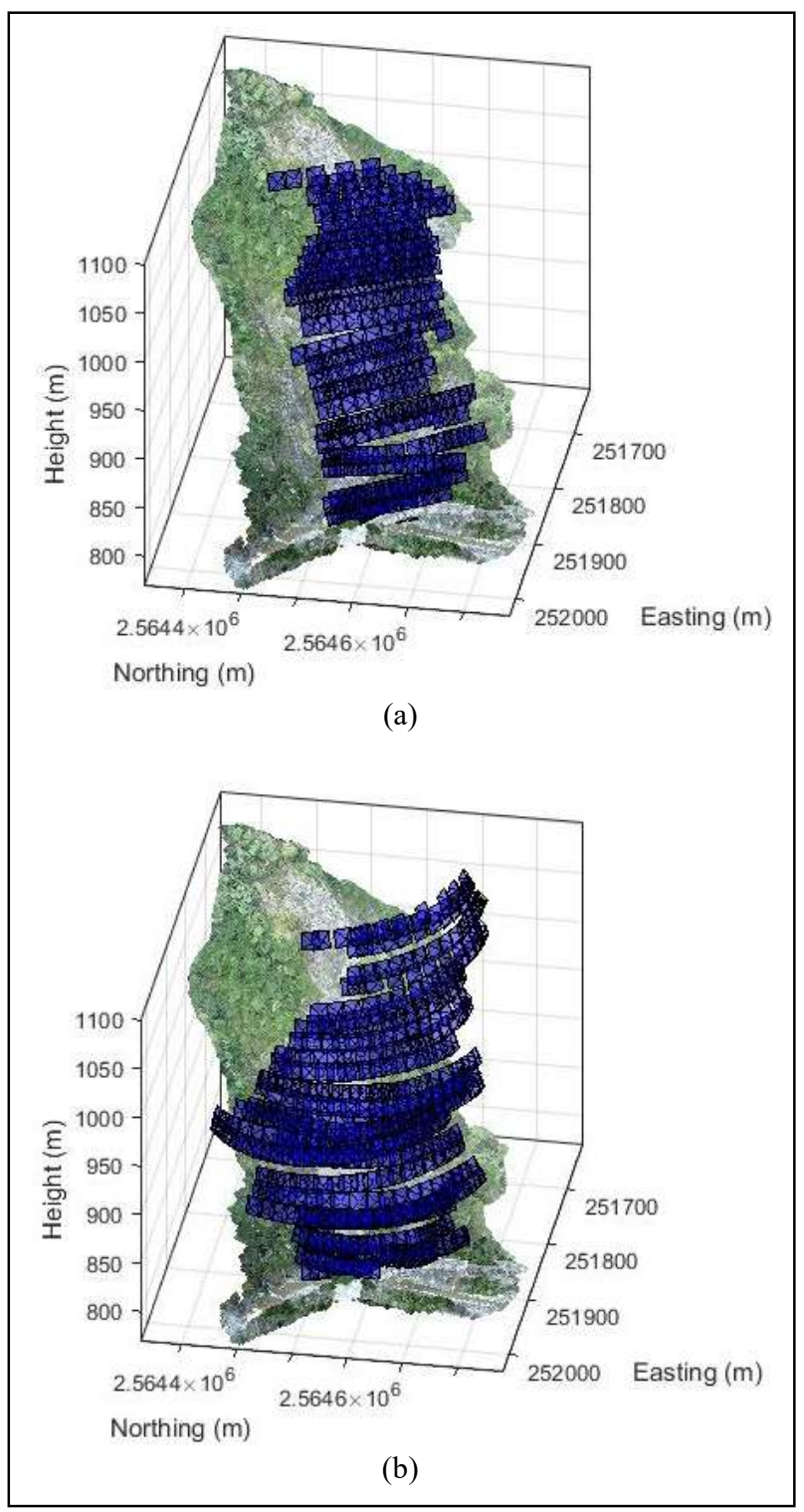

Figure 4. Camera position and orientation of flight plans operated by P4RTK. (a) straight flight lines and (b) semicircular flight lines.

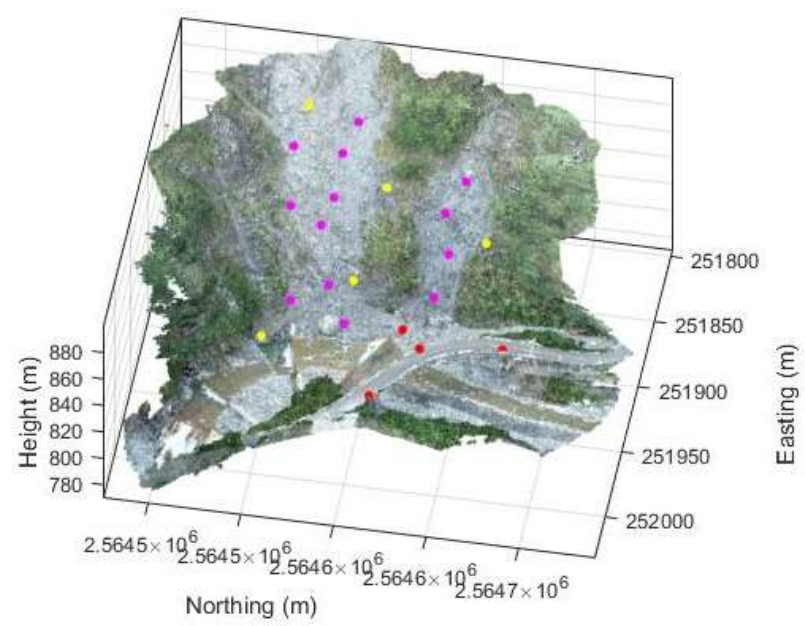

Figure 5. Distribution of control points (yellow on the landslide and red on the bridge) and check points (pink). 
To avoid area distortion after projecting source data to a XY plane to produce DSM, Rodrigues' rotation formula was applied to transform the point cloud data to roughly fit the XY plane. The first step was creating an XYZ function plane, which fitted the point cloud by the least-square methods. Then calculate rotation axis vector and angle by the normal vectors of fitting plane and $\mathrm{XY}$ plane. Finally carry out the rotation matrix and multiply it by dense point cloud. The formula is as following:

$$
V_{\text {rot }}=V \cos \theta+(K \times V) \sin \theta+K(K \cdot V)(1-\cos \theta)
$$

Where

$$
\begin{aligned}
& V_{\text {rot }}=\text { rotation matrix } \\
& K=\text { rotation axis unit vector } \\
& V=\text { the normal vector of fitting plane } \\
& \theta=\text { angle between } V \text { and } K
\end{aligned}
$$

\section{RESULT}

Two periods of UAV photographed aerial images were processed by SfM workflow to produce dense point cloud (Figure 6, 7). In the $2^{\text {nd }}$ survey, 4 kinds of flight design combined 4 kinds of GCP spreading geometry were all processed in SfM with the same parameters setting to produce dense point cloud. The accuracy of the total 16 models were compared by RMSE of check points and the best one was selected to calculating distance change with $1^{\text {st }}$ survey model by $\mathrm{M} 3 \mathrm{C} 2$ algorithm. Because the GCPs did not cover the whole extent of landslide and prevent error exaggeration with extrapolation, the study area was reduced to smaller one which was within the coverage of GCPs geometry. Meanwhile, to maintain the complete shape of point cloud, the reduced area was divided into two parts (area No.1 and area No. 2, see Figure 7) and calculate $\mathrm{M} 3 \mathrm{C} 2$ distance and volume respectively. The $\mathrm{M} 3 \mathrm{C} 2$ distance revealed the sub regional change of the whole target surface (Figure 8). Then rotate the point clouds to roughly fit the XY plane (Figure 9) and extract significant change area into ArcGIS estimating the volume change (Figure 10)

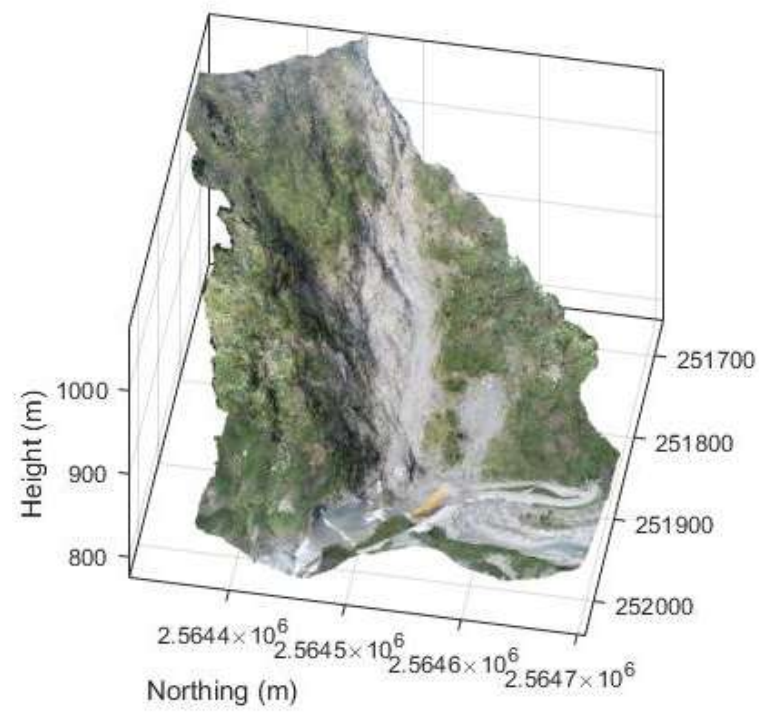

Figure 6. Dense point cloud of the landslide on $1^{\text {st }}$ survey

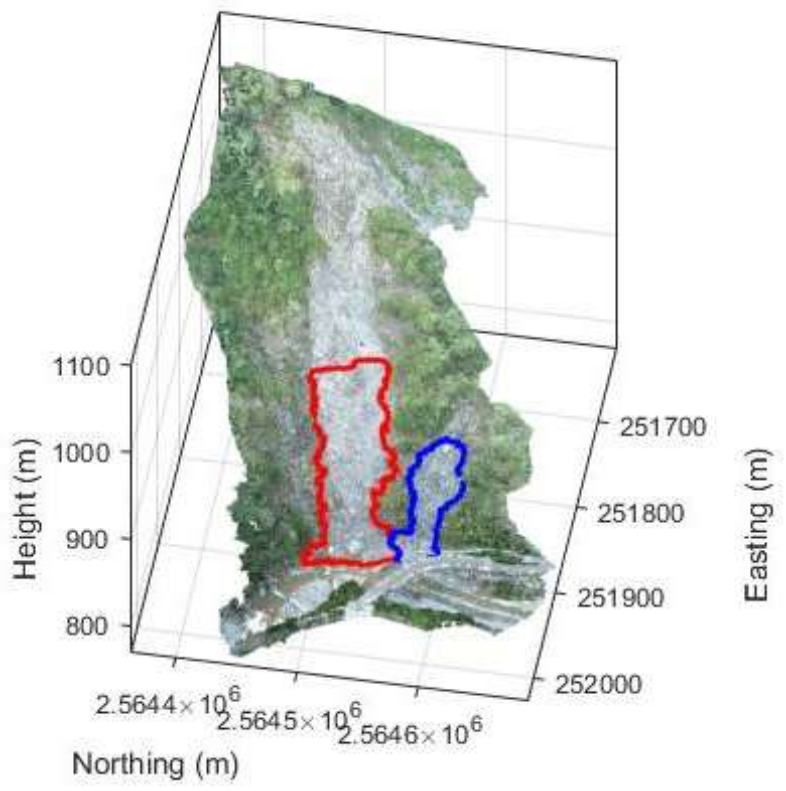

Figure 7. Dense point cloud of the landslide in $2^{\text {nd }}$ survey, area No. 1 (red) and area No. 2 (blue) are taken into further study.

\subsection{Accuracy Assessment}

The accuracy assessment of models, which is influenced by different settings of flight course, UAV types, and ground reference geometries, are evaluated by RMSE of check points of models. For the different selection of GCPs geometry, without GCPs on the bridge, the RMSE of check points have no significant difference from models with full 9 GCPs no matter what kind of flight course and UAVs selected. In contrast, without 5 GCPs on landslide surface, the RMSE of check points have enlarged by 1.4 1.9 times than that of models with full 9 GCPs in different combination of flight course and UAV types.

For different selection of UAVs, the test was done without georeferencing information as outside constrain. SfM carrying out bundle adjustment only relies on camera parameters recorded from GPS systems mounted on UAV. when camera positions recorded by P4P Pro are used as extrinsic parameters in SfM procedures, the RMSE of check points in $\mathrm{Z}$ direction are over $70 \mathrm{~m}$, and RMSE in the horizontal direction also enlarged maximum to $5 \mathrm{~m}$, no matter what kind of flight courses was chosen. In contrast, when camera positions recorded by P4RTK are used as exterior parameters, the RMSE of horizontal direction significantly decrease to $2.33 \mathrm{~m}$ and $0.986 \mathrm{~m}$ with semi-circular and straight flight lines respectively, and vertical direction decrease to $1.427 \mathrm{~m}$ and $7.976 \mathrm{~m}$.

With only 4 GCPs on the bridge, the RMSE values of models are slightly larger than that with 5 GCPs both in horizontal and vertical direction, no matter what kinds of UAV types or flight lines design.

For the different combination of flight course design, there is no significant difference of RMSE of models between two kinds of flight courses in the condition that the full 9 GCPs were used and UAVs are the same. The result suggests that semi-circular and straight flight lines cause no significant difference in the UASSfM workflow (Table 1). 


\begin{tabular}{|c|c|c|c|c|}
\hline & \multicolumn{4}{|c|}{ Semi-circular } \\
\hline Platform & \multicolumn{2}{|c|}{ P4P } & \multicolumn{2}{c|}{ P4RTK } \\
\hline RMSE(m) & XY & $Z$ & XY & $Z$ \\
\hline 9 GCPs & 0.059 & 0.037 & 0.034 & 0.035 \\
\hline No GCPs & 5.09 & 76.955 & 2.330 & 1.427 \\
\hline 5 GCPs & 0.069 & 0.039 & 0.041 & 0.034 \\
\hline 4 GCPs & 0.113 & 0.050 & 0.055 & 0.072 \\
\hline
\end{tabular}

\begin{tabular}{|c|c|c|c|c|}
\hline & \multicolumn{4}{|c|}{ Straight } \\
\hline Platform & \multicolumn{2}{|c|}{ P4P } & \multicolumn{2}{c|}{ P4RTK } \\
\hline RMSE(m) & XY & $Z$ & XY & $Z$ \\
\hline 9 GCPs & 0.045 & 0.052 & 0.037 & 0.033 \\
\hline No GCPs & 4.744 & 74.984 & 0.986 & 7.976 \\
\hline 5 GCPs & 0.054 & 0.044 & 0.039 & 0.033 \\
\hline 4 GCPs & 0.047 & 0.102 & 0.046 & 0.052 \\
\hline
\end{tabular}

Table 1. Errors of flight design with GCPs distribution geometry

\subsection{Volume Calculation}

The volumetric estimation of landslide morphological change between the two periods of point clouds shows, 5 parts with significant loss and 5 parts with significant gain. The mean $95 \%$ confidence of detectable change is $0.1 \mathrm{~m}$. In the decrease parts, the volume changes are $2404 \pm 194 \mathrm{~m}^{3}, 389 \pm 93 \mathrm{~m}^{3}, 97 \pm 40 \mathrm{~m}^{3}$, $634 \pm 55 \mathrm{~m}^{3}$ and $858 \pm 114 \mathrm{~m}^{3}$ respectively. In the increase parts, the volume changes are $96 \pm 18 \mathrm{~m}^{3}, 132 \pm 13 \mathrm{~m}^{3}, 49 \pm 10 \mathrm{~m}^{3}, 350 \pm 44$ $\mathrm{m}^{3}$ and $51 \pm 14 \mathrm{~m}^{3}$. The total volume loss is $4832 \pm 496 \mathrm{~m}^{3}$ and volume gain is $678 \pm 99 \mathrm{~m}^{3}$, which means there were about 4000 $\mathrm{m}^{3}$ collapse eroded during 10 months (Figure 10, 11).

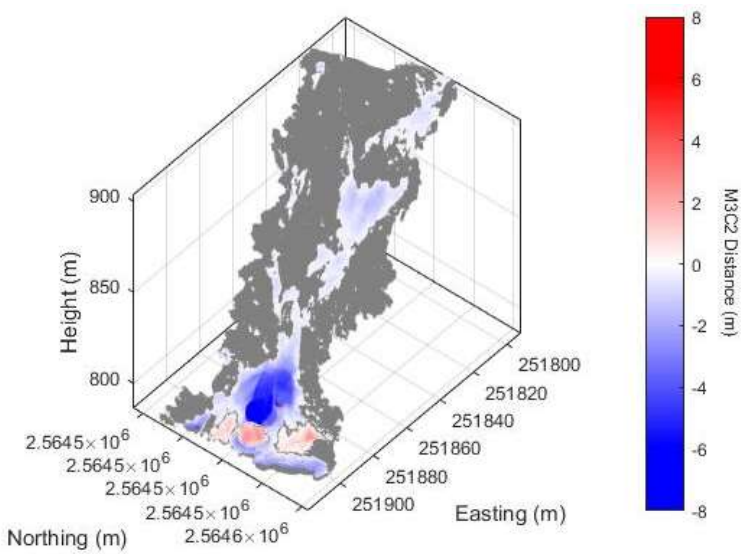

(a) M3C2 distance of area No. 1

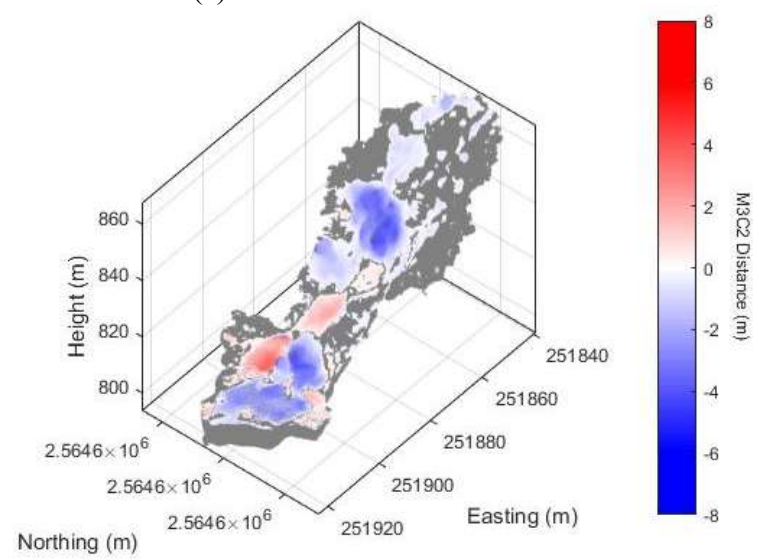

(b) $\mathrm{M} 3 \mathrm{C} 2$ distance of area No. 2

Figure $8 . \mathrm{M} 3 \mathrm{C} 2$ distance of further studied area

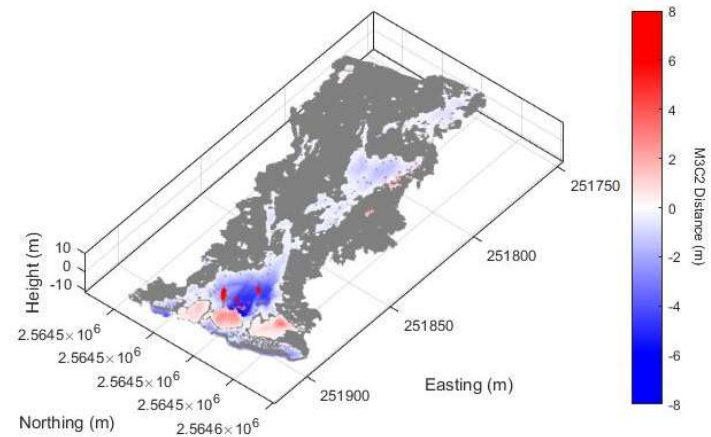

(a) Transformed area No. 1

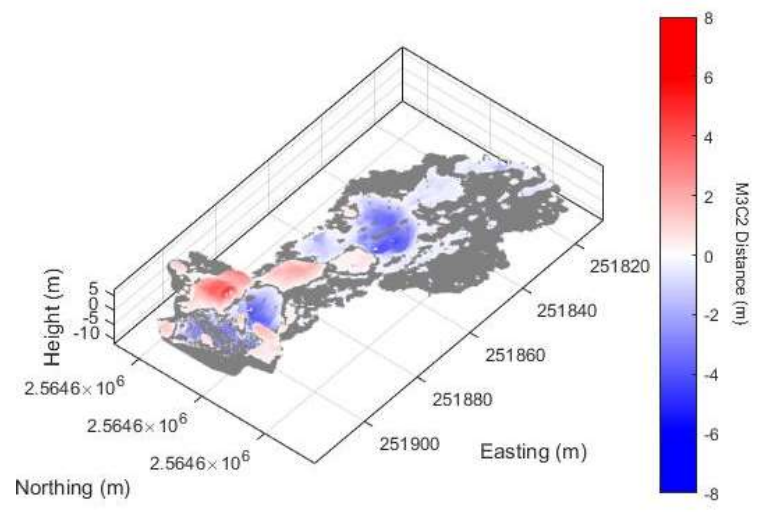

(b) Transformed area No. 2

Figure 9. Transformed further studied area

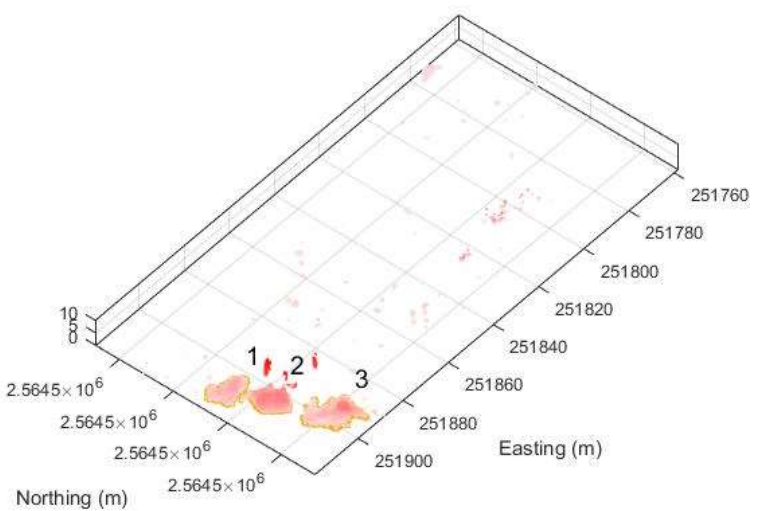

(a)

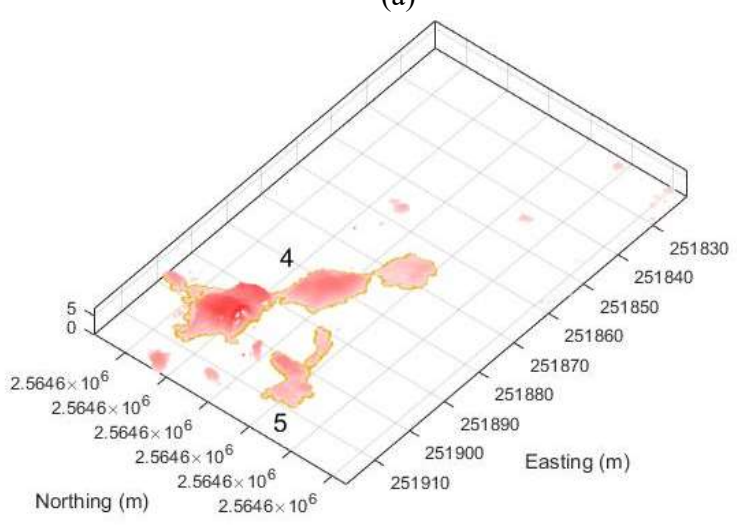

(b)

Figure 10. Significant increase part. (a) $1^{\text {st }}, 2^{\text {nd }}$ and $3^{\text {rd }}$ part on area No. 1 (b) $4^{\text {th }}$ and $5^{\text {th }}$ part on area No. 2 


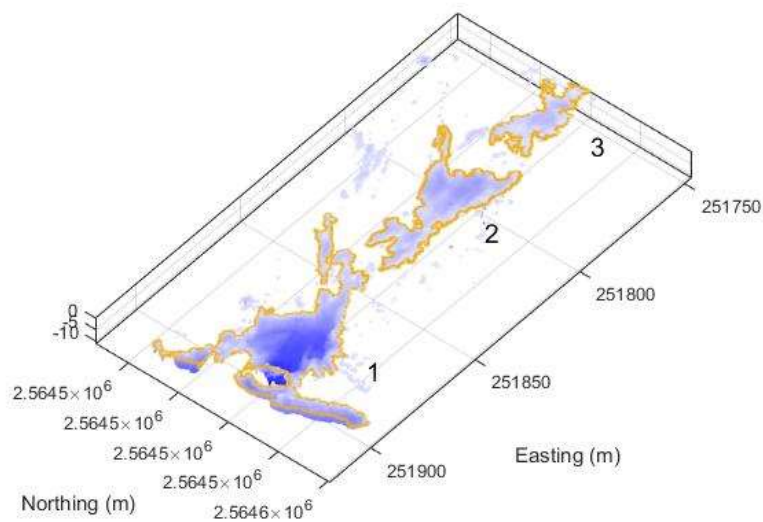

(a)

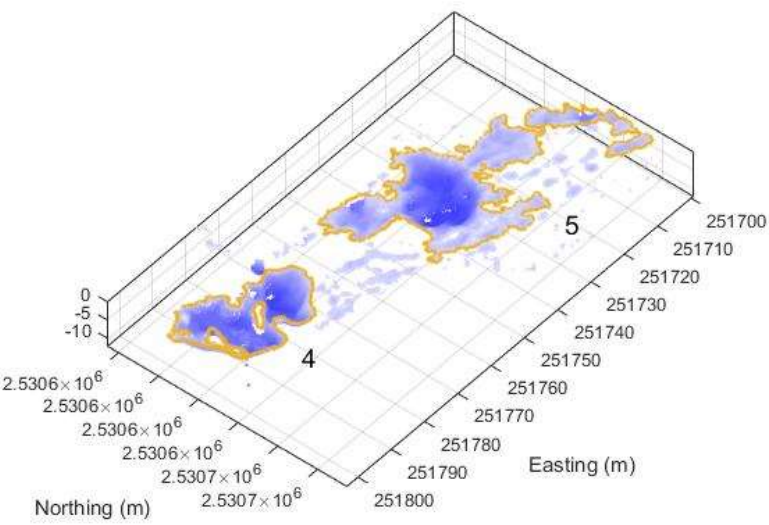

(b)

Figure 11. Significant decrease part. (a) $1^{\text {st }}, 2^{\text {nd }}$ and $3^{\text {rd }}$ part on area No. 1 (b) $4^{\text {th }}$ and $5^{\text {th }}$ part on area No. 2

\section{CONCLUSION}

To acquire and analyse detailed morphological information of landslide with extreme topography, the UAV-SfM workflow has proven to be a suitable method and can be applied on multi temporal monitoring of landslides with low cost. In this study, we examined different observation settings by using UAVs and deploying GCPs for a landslide with extreme topography within an active mountain belt in south eastern Taiwan. Our results show that when applying the UAV-SfM methods on steep targets, the flight line should be arranged vertically on different elevation so that the images can contain the full extent of façade, which help produce enough tie points in SfM processing. Appropriate flight design and GCPs geometry can improve the quality of 3D models. Shape of flight line cause no significant difference for observing landslides on single slope. However, RTK-UAVs can improve the accuracy of 3D models significantly, especially in the area where GCPs are not available. For volume estimation, after the rotation, the distortion of the projection in DSM creation can be modified.

\section{REFERENCES}

Agüera-Vega, F., Carvajal-Ramírez, F., Martínez-Carricondo, P., Sánchez-Hermosilla López, J., Mesas-Carrascosa, F. J., GarcíaFerrer, A., Pérez-Porras, F. J., 2018: Reconstruction of extreme topography from UAV structure from motion photogrammetry. Measurement, 121 , 127-138.
Clapuyt, F., Vanacker, V., Schlunegger, F., Kristof, V. O., 2017: Unravelling earth flow dynamics with 3-D time series derived from UAV-SfM models. Earth Surface Dynamics, 5(4), 791-806. doi.org/10.5194/esurf-5-791-2017.

Eltner, A., Kaiser, A., Castillo, C., Rock, G., Neugirg, F., Abellan, A., 2016: Image-based surface reconstruction in geomorphometry - merits, limits and developments. Earth Surface Dynamics, 4(2), 359-389. doi.org/10.5194/esurf-4-3592016.

Esposito, G., Salvini, R., Matano, F., Sacchi, M., Danzi, M., Somma, R., Troise, C., 2017: Multitemporal monitoring of a coastal landslide through SfM-derived point cloud comparison. The Photogrammetric Record, 32(160), 459-479. doi.org/10.1111/phor.12218.

Jaud, M., Letortu, P., Théry, C., Grandjean, P., Costa, S., Maquaire, O., Davidson, R., Le Dantec, N., 2019: UAV survey of a coastal cliff face - Selection of the best imaging angle. Measurement, 139, 10-20. doi.org/10.1016/j.measurement.2019.02.024

Lague, D., Brodu, N., Leroux, J., 2013: Accurate 3D comparison of complex topography with terrestrial laser scanner: Application to the Rangitikei canyon (N-Z). ISPRS Journal of Photogrammetry and Remote Sensing, 82, 10-26. doi.org/10.1016/j.isprsjprs.2013.04.009.

Lucieer, A., Jong, S. M. d., Turner, D., 2014: Mapping landslide displacements using Structure from Motion (SfM) and image correlation of multi-temporal UAV photography. Progress in Physical Geography, 38(1), 97-116. doi.org10.1177/0309133313515293.

Niethammer, U., James, M., Rothmund, S., Travelletti, J., Joswig, M., 2012: UAV-based remote sensing of the Super-Sauze landslide: Evaluation and results. Engineering Geology, 128, 211. doi.org/10.1016/j.enggeo.2011.03.012.

Stumpf, A., Malet, J. P., Allemand, P., Pierrot-Deseilligny, M., Skupinski, G., 2015: Ground-based multi-view photogrammetry for the monitoring of landslide deformation and erosion. Geomorphology, 231, 130-145. doi.org/10.1016/j.geomorph.2014.10.039.

Turner, D., Lucieer, A., de Jong, S., 2015: Time Series Analysis of Landslide Dynamics Using an Unmanned Aerial Vehicle (UAV). remote sensing, 7(2), 1736. doi.org/10.3390/rs70201736.

Warrick, J. A., Ritchie, A. C., Schmidt, K. M., Reid, M. E., Logan, J., 2019: Characterizing the catastrophic 2017 Mud Creek landslide, California, using repeat structure-from-motion (SfM) photogrammetry. Landslides, 16(6), 1201-1219. doi.org/s10346019-01160-4. 